\title{
CORRIGENDUM
}

\section{A dietary survey to determine if patients with coeliac disease are meeting current healthy eating guidelines and how their diet compares to that of the British general population}

\author{
L Kinsey, ST Burden and E Bannerman
}

European Journal of Clinical Nutrition (2011) 65, 283; doi:10.1038/ejcn.2010.256

Correction to: European Journal of Clinical Nutrition (2007) 62, 1333-1342; doi:10.1038/sj.ejcn.1602856

Since the publication of this paper, the authors have noticed an error in the headings of Table 3 (Males and Females). The correct table is shown here.

Table 3 Mean intake of nutrients (s.d.) in patients with coeliac disease compared to the general population

\begin{tabular}{|c|c|c|c|c|}
\hline \multirow[t]{2}{*}{ Daily intakes } & \multicolumn{2}{|c|}{ Females } & \multicolumn{2}{|c|}{ Males } \\
\hline & Coeliacs & NDNS & Coeliacs & NDNS \\
\hline $19-64$ years $^{a}$ & $(n=22)$ & $(n=891)$ & $(n=6)$ & $(n=833)$ \\
\hline Energy (kcal) & $1754 \pm 403$ & $1632 \pm 418$ & $2039 \pm 124$ & $2313 \pm 582^{*}$ \\
\hline Energy (kł) & $7338 \pm 1687$ & $6870 \pm 1758$ & $8530 \pm 518$ & $9720 \pm 2446^{*}$ \\
\hline Protein $(g)$ & $83 \pm 24$ & $64 \pm 17^{\star}$ & $77 \pm 10$ & $88 \pm 33^{*}$ \\
\hline Fat (g) & $64 \pm 20$ & $61.4 \pm 21.7$ & $69 \pm 11$ & $87 \pm 28.2^{*}$ \\
\hline $\mathrm{CHO}(\mathrm{g})$ & $219 \pm 65$ & $203 \pm 59$ & $262 \pm 31$ & $275 \pm 79$ \\
\hline NSP $(g)$ & $12 \pm 5$ & $12.6 \pm 5.0$ & $16 \pm 5$ & $15.2 \pm 6.0$ \\
\hline Folate $(\mu \mathrm{g})$ & $251 \pm 120$ & $251 \pm 90$ & $258 \pm 68$ & $344 \pm 127^{*}$ \\
\hline Vitamin B12 $(\mu \mathrm{g})$ & $6.9 \pm 10.0$ & $4.8 \pm 2.7$ & $5.1 \pm 1.5$ & $6.5 \pm 4.7$ \\
\hline Vitamin $\mathrm{D}(\mu \mathrm{g})$ & $2.7 \pm 2.07$ & $3.7 \pm 2.3^{*}$ & $3.1 \pm 3$ & $2.8 \pm 2.1$ \\
\hline Iron (mg) & $9.9 \pm 3.3$ & $10.0 \pm 3.7$ & $11.7 \pm 5.5$ & $10.0 \pm 3.7$ \\
\hline Calcium (mg) & $807 \pm 283$ & $777 \pm 269$ & $1076 \pm 207$ & $1007 \pm 411$ \\
\hline$>65$ years $^{\mathrm{b}}$ & $(n=13)$ & $(n=891)$ & $(n=6)$ & $(n=632)$ \\
\hline Energy (kcal) & $1918 \pm 503$ & $1909 \pm 465$ & $1457 \pm 331$ & $1374 \pm 337$ \\
\hline Energy (kJ) & $8346 \pm 1919$ & $8020 \pm 195$ & $6096 \pm 1385$ & $5970 \pm 1410$ \\
\hline Protein (g) & $83 \pm 21$ & $72 \pm 17$ & $60 \pm 15$ & $56 \pm 13$ \\
\hline Fat $(g)$ & $56 \pm 28$ & $75 \pm 24^{*}$ & $49 \pm 12$ & $58 \pm 18$ \\
\hline $\mathrm{CHO}(\mathrm{g})$ & $277 \pm 88$ & $232 \pm 64$ & $201 \pm 60$ & $175 \pm 47$ \\
\hline NSP (g) & $13.4 \pm 3.3$ & $13.5 \pm 5.8$ & $11.8 \pm 4.7$ & $11 \pm 4.7$ \\
\hline Folate $(\mu \mathrm{g})$ & $339 \pm 189$ & $270 \pm 95$ & $214 \pm 61$ & $207 \pm 75$ \\
\hline Vitamin B12 $(\mu \mathrm{g})$ & $4.1 \pm 2.1$ & $6.1 \pm 6.2^{*}$ & $2.7 \pm 1.2$ & $4.5 \pm 4.4$ \\
\hline Vitamin D $(\mu \mathrm{g})$ & $2.7 \pm 1.7$ & $4.07 \pm 3.2^{\star}$ & $1.9 \pm 1.4$ & $2.9 \pm 2.4$ \\
\hline Iron (mg) & $11.9 \pm 4.6$ & $11.0 \pm 3.6$ & $7.5 \pm 3.3$ & $8.6 \pm 2.9$ \\
\hline Calcium (mg) & $1074 \pm 430$ & $836 \pm 285$ & $798 \pm 365$ & $690 \pm 246$ \\
\hline
\end{tabular}

Abbreviations: CD, coeliac disease; $\mathrm{CHO}$, carbohydrate; NSP, non-starch polysaccharide.

${ }^{*} P<0.05$; one sample $t$-test. Dietary intakes of $C D$ patients are significantly different from dietary intakes of the general UK population.

aNDNS, 2003a.

bNDNS, 1998.
In addition, there are five instances where Table 3 is incorrectly cited. These are all in the section 'Results compared to the DRVs' and are listed as follows:

Page 3, right-hand column, line 3

Page 4, left-hand column, line 4

Page 4, left-hand column, line 2

Page 4, right-hand column, line 10

Page 4, right-hand column, line 31

The authors would like to apologize for this error. 